\title{
Cysteine proteinase inhibitor cystatin $C$ in squamous cell carcinoma of the head and neck: relation to prognosis
}

\author{
P Strojan ${ }^{*, 1}$, I Oblak', B Svetic ${ }^{2}$, L Šmid ${ }^{3}$ and J Kos ${ }^{4,5}$ \\ 'Department of Radiotherapy, Institute of Oncology, SI-I 000 Ljubljana, Slovenia; ${ }^{2}$ Department of Biochemistry, Institute of Oncology, SI-I 000 Ljubljana, \\ Slovenia; ${ }^{3}$ University Department of Otorhinolaryngology and Cervicofacial Surgery, Clinical Center, SI- 1000 Ljubljana, Slovenia; ${ }^{4}$ Department of \\ Pharmaceutical Biology, Faculty of Pharmacy, University of Ljubljana, SI- 1000 Ljubljana, Slovenia; ${ }^{5}$ Department of Biochemical Research and Drug Design, \\ KRKA, d.d., SI-IO00 Ljubljana, Slovenia
}

To determine the role of the cysteine proteinase inhibitor cystatin $C$ in the invasive behavior of squamous cell carcinoma of the head and neck (SCCHN), Cystatin C protein level was measured in 82 pairs of primary tumour tissue and adjacent noncancerous mucosa, using the enzyme-linked immunosorbent assay. The median level of cystatin $C$ in tumour tissue was I. 8 times lower than that in corresponding mucosa $(P=0.031)$. In normal mucosa samples, the cystatin $C$ level was influenced by the site of sampling: it was lower in nonlaryngeal tissue samples (oral cavity, oro- or hypopharynx) than in laryngeal samples $(P=0.004)$. The tumour cystatin $C$ level correlated inversely with $\mathrm{pN}$-stage $(P=0.047)$, whereas a trend of lower cystatin $C$ levels was observed in the group with extranodal tumour extension compared to those with no extranodal spread $(P=0.069)$. In univariate analysis, the patients with low tumour cystatin $C$ levels exhibited poor disease-free survival (DFS, $P=0.013$ ) and disease-specific survival (DSS, $P=0.013$ ). In multivariate analysis, the most powerful predictor of survival was $\mathrm{pN}$-stage (DFS: $P=0.040, \mathrm{HR} 2.78$; $D S S: P=0.01 \mathrm{I}, \mathrm{HR}$ 4.36,), followed by the cystatin C level (DFS: $P=0.043$, HR 0.22; DSS: $P=0.067, \mathrm{HR} 0.25$ ). When comparing the prognostic strength of cystatin $C$ to that of stefin $A$, another cysteine proteinase inhibitor, which emerged as the most significant prognosticator for survival in our previous study analysing the same cohort of patients, stefin A proved to be significantly more reliable predictor for both DFS and DSS than cystatin C. Our results indicate that cystatin $\mathrm{C}$ is implicated in the invasive behavior of SCCHN, and that there are variations in regulation of proteolytic pathways under nonmalignant conditions, inherent to individual subsites inside the upper aerodigestive tract. The correlation between high cystatin $C$ levels and improved survival concurs with the concept of the protective role of high levels of cysteine proteinase inhibitors in tissue homogenates that has been previously suggested by the survival results in breast and lung carcinoma as well as SCCHN.

British Journal of Cancer (2004) 90, 196 I-1968. doi:I0.1038/sj.bjc.660I830 www.bjcancer.com

Published online 27 April 2004

(c) 2004 Cancer Research UK

Keywords: cystatin C; head and neck cancer; squamous cell carcinoma; prognosis

Cystatin $\mathrm{C}$ is a nonglycosylated $13 \mathrm{kDa}$ basic protein, consisting of 120 amino acids. It belongs to the cystatin superfamily of cysteine proteinase inhibitors. Cystatin $\mathrm{C}$ is produced at a constant rate by all nucleated cells as a preprotein with a hydrophobic leader sequence of 26 amino acids, indicating an extracellular function of the inhibitor. Cystatin C protein is a product of the CST3 gene, which is located on the short arm of chromosome 20. It is freely filtered in the glomeruli and almost completely reabsorbed and catabolised in the proximal renal tubular cells (Newman, 2002). The main physiological role of cystatin $C$ is believed to be the regulation of cysteine proteinases secreted from the cells or leaked from the lysosomes during necrotic or apoptotic processes, which links cystatin $\mathrm{C}$ with the aetiology of various diseases, including cancer (Sloane et al, 1994).

*Correspondence: Dr P Strojan; E-mail: pstrojan@onko-i.si

Supported by the Ministry of Education, Science and Sport of the Republic of Slovenia Grant J3-4308.

Received 5 December 2003; revised 18 February 2004; accepted 3 March 2004; published online 27 April 2004
Immunohistochemically, cystatin $\mathrm{C}$ protein was stained intracellularly in the cytoplasmic compartment of tumour cells in a variety of cancer types (Lignelid and Jacobsson, 1992; Lignelid et al, 1997; Yoshimura et al, 2000; Gaumann et al, 2001; Hansen et al, 2001; Yano et al, 2001). The mechanisms controlling the intracellular inhibition of cysteine proteinases in endosomes and lysosomes with cystatin $\mathrm{C}$ entering the endosomal-lysosomal pathway by endocytotic uptake may include dimerisation (Ekiel and Abrahamson, 1996; Merz et al, 1997), proteolytic fragmentation by cathepsin D (Lenarčič et al, 1991) or neutrophilic granulocyte elastase (Abrahamson et al, 1991). Some of these mechanisms may operate already in the pericellular microenvironment and may restrict the inhibitory function of the secreted cystatin $\mathrm{C}$ against the proteolytic activity of cell surface associated and/or secreted enzymes (Křepela et al, 1998).

Immunohistochemical quantification of cystatin $\mathrm{C}$ expression suggested that the concentration of immunoreactive protein in the cells of some tumour types seems to be below the detection limit. In the study by Lignelid et al (1997), for example, only a minority of cystatin C mRNA positive brain and pituitary tumours revealed cystatin C-immunoreactive tumour cells. In a group of 88 
meningiomas, Strojnik et al (2001) detected no immunostaining for cystatin C in any of the tumours, although Lignelid et al (1997) reported a $100 \%$ positivity for cystatin $C$ transcripts in meningiomas. Alternatively, in homogenised preparations used for cystatin $\mathrm{C}$ mRNA determination, cystatin $\mathrm{C}$ expressing noncancerous stromal cells within tumours with otherwise low expression level of cystatin $\mathrm{C}$ in their cancer cells may contribute substantially to the total cystatin C mRNA level (Lignelid et al, 1997). The same reproach regarding the origin of cystatin $\mathrm{C}$ holds true when immunobiochemical methods are used for the determination of cystatin $\mathrm{C}$ levels in tissue homogenates. However, a large body of evidence proved the tissue homogenate levels of proteinases and inhibitors of various classes to be of significant clinical relevance (Foekens et al, 1998; Look et al, 2002).

The role of cystatin $\mathrm{C}$ in the invasive behavior of squamous cell carcinoma of the head and neck (SCCHN) has not been investigated so far. The aim of the present study was to determine the levels of cystatin $\mathrm{C}$ in the tissue homogenates of SCCHN and its surrounding noncancerous mucosa. As SCCHN is an extremely heterogenous disease, it is little surprise that no factor within the wide spectrum of biochemical and histological factors has yet been identified as reliably predicting the natural course of the disease or its response to therapy (Lal, 1994; Quon et al, 2001). Thus, the results of the study have been related to established clinical and histopathological features, considering especially the correlation of individual tumour levels of cystatin $\mathrm{C}$ with patients' survival.

\section{MATERIALS AND METHODS}

\section{Patients}

In total, 82 previously untreated patients with primary operable SSCHN entered the study. Of these patients, five were females and 77 males, ranging in age from 37 to 72 years (median age: 59 years). This cohort of patients was the same as in our previous report, examining the prognostic significance of cysteine proteinases cathepsins $B$ and $\mathrm{L}$ and their intracellular inhibitors $\mathrm{A}$ and $\mathrm{B}$ (Strojan et al, 2000).

In all patients, therapeutic surgery was performed. It comprised the resection of the primary tumour, related to the lesion extension, together with a surrounding margin of normal tissue, and removal of the related regional lymph nodes from the neck. Postoperative radiotherapy was applied in 74 patients, because of an advanced stage of disease, extranodal tumour spread, residual growth after surgery, or the presence of neoplastic emboli in the lymphatic vessels. The patients were irradiated on a Cobalt- 60 unit or a 5-MV linear accelerator, with a daily dose of $1.8-2.0 \mathrm{~Gy}, 5$ days per week. Radiotherapy doses were adapted to the disease extent and ranged from 50 to $66 \mathrm{~Gy}$ (median dose: $56 \mathrm{~Gy}$ ), It was delivered through two opposing lateral fields to the primary tumour and regional lymph nodes, with spinal cord shielded after a dose of $40-44 \mathrm{~Gy}$. One anterior field was added to cover the lower neck lymphatics.

Tumours were staged according to UICC pTNM classification after histopathological examination of surgical specimens (Sobin and Wittekind, 1997). The histopathological grade was defined according to WHO criteria (Azzopardi et al, 1981). Clinical and histopathological characteristics of tumours are shown in Table 1.

\section{Sample collection}

From operative specimen, two tissue samples of $200-500 \mathrm{mg}$, representing matched pairs, were obtained from the tumour and adjacent normal mucosa. Immediately after removal, they were immersed in liquid nitrogen until homogenate preparation. Fat and necrotic parts were carefully removed. Pulverisation was performed on the frozen tissue with a Mikro-Dismembranator
Table I Tumour parameters of 82 patients with operable squamous cell carcinoma of the head and neck

\begin{tabular}{|c|c|c|c|c|c|}
\hline \multicolumn{6}{|l|}{ Primary tumour site } \\
\hline Oral cavity & 14 & & & & \\
\hline Oropharynx & 18 & & & & \\
\hline Hypopharynx & 10 & & & & \\
\hline Larynx & 40 & & & & \\
\hline \multicolumn{6}{|l|}{ UICC pTNM-classification } \\
\hline & $\mathrm{N}_{0}$ & $N_{1}$ & $\mathrm{~N}_{2}$ & $\mathrm{~N}_{3}$ & Total \\
\hline $\mathrm{T}_{1}$ & 3 & । & 2 & 0 & 6 \\
\hline $\mathrm{T}_{2}$ & | | & 3 & 13 & । & 28 \\
\hline $\mathrm{T}_{3}$ & 14 & । & 9 & 0 & 24 \\
\hline $\mathrm{T}_{4}$ & 9 & 2 & 13 & 0 & 24 \\
\hline Total & 37 & 7 & 37 & । & 82 \\
\hline \multicolumn{6}{|l|}{ Overall stage } \\
\hline Stage $_{\mid}$ & 3 & & & & \\
\hline Stage $_{\|}$ & 12 & & & & \\
\hline Stage $_{\| I}$ & 19 & & & & \\
\hline Stage $_{\mathrm{IV}}$ & 48 & & & & \\
\hline \multicolumn{6}{|l|}{ Histopathological grading } \\
\hline Well differentiated, $\mathrm{G}_{1}$ & 3 & & & & \\
\hline Moderately differentiated, $\mathrm{G}_{2}$ & 68 & & & & \\
\hline Poorly differentiated, $\mathrm{G}_{3}$ & II & & & & \\
\hline \multicolumn{6}{|l|}{ Extranodal extention $^{\text {a }}$} \\
\hline Negative & 15 & & & & \\
\hline Positive & 30 & & & & \\
\hline \multicolumn{6}{|c|}{ Tumour emboli in lymph node vessels ${ }^{\mathrm{a}}$} \\
\hline Negative & 37 & & & & \\
\hline Positive & 8 & & & & \\
\hline
\end{tabular}

${ }^{\mathrm{a}} \mathrm{p} \mathrm{N}_{+}$patients only, $n=45$.

(Braun, Melsungen, Germany) for $60 \mathrm{~s}$ at maximum power, and the resulting tissue powder was suspended in an extraction buffer consisting of $5 \mathrm{mM} \mathrm{Na} \mathrm{HPO}_{4}, 1 \mathrm{mM}$ monothioglycerol, and $10 \%$ $\mathrm{vv}^{-1}$ glycerol ( $\mathrm{pH} 7.4$ ). The suspension was centrifuged for $45 \mathrm{~min}$ at $100000 \times \mathbf{g}$ to obtain a supernatant, that is homogenate, which was divided into aliquots and stored at $-70^{\circ} \mathrm{C}$ until use.

\section{Determination of cystatin C}

Cystatin C concentrations were determined by enzyme-linked immunosorbent assay (KRKA d.d., Novo mesto, Slovenia). Recombinant human cystatin C was expressed in Escherichia coli as described (Cimerman et al, 1999) and used for the immunisation of animals and the preparation of calibration curves. Rabbit polyclonal antibody (IgG), purified from antisera by affinity chromatography on immobilised cystatin C, was used as capture antibody and murine $1 \mathrm{~A} 2$ monoclonal antibody, conjugated to horseradish peroxidase, was used for detection (Kos et al, 2000a). Antibodies were specific for recombinant and native human cystatin $\mathrm{C}$, and recognised free inhibitor and cathepsin-inhibitor complexes. Crossreactivity between closely related inhibitors of cysteine proteinases (human stefins A and B) was excluded by immunoblot and ELISA.

Linearity and recovery of ELISA was tested as described (Kos et al, 2000a). A microplate reader was used to measure the absorbance (SLT Rainbow, Salzburg, Austria) in ELISA. The concentration of cystatin $\mathrm{C}$ was expressed in $\mathrm{ng} \mathrm{mg}^{-1}$ of total protein (ng mgp ${ }^{-1}$ ).

Tumour samples at $1: 20$ dilution and normal tissue samples at $1: 10$ dilution were added to the wells of a microtitre plate precoated with rabbit anticystatin C IgG. After $2 \mathrm{~h}$ of incubation at 
$37^{\circ} \mathrm{C}$, the wells were washed and murine monoclonal $1 \mathrm{~A} 2$ anticystatin $\mathrm{C}$ antibody, which was purified by the affinity chromatography on Protein A-Sepharose and conjugated subsequently with horseradish peroxidase, was added. After a further $2 \mathrm{~h}$ of incubation at $37^{\circ} \mathrm{C}, 3,3,4,4$-tetramethyl benzidine (Sigma, St Louis, MO, USA) in the presence of hydrogen peroxide was added. The amount of degraded substrate, as a measure of bound immunocomplexed cystatin $\mathrm{C}$, was visualised by absorbance at $450 \mathrm{~nm}$. The cystatin $\mathrm{C}$ concentration was calculated from the calibration curve.

\section{Determination of proteins}

Protein concentrations were determined according to the Bradford method (Bradford, 1976). Bovine serum albumin was used as a standard.

\section{Statistical analysis}

The results were analysed using a PC and the SPSS statistical package (Release 10.0, SPSS Inc., Chicago, IL, USA). The difference between the median concentrations of cystatin $C$ in matched pairs of tumour and normal tissue samples was determined by the Wilcoxon signed-rank test. The Mann - Whitney $U$ test was used to test the relationship between the median values of the tumour tissue cystatin $\mathrm{C}$ concentrations in different groups of patients. The difference in distribution of pTNM-stages between the patients with laryngeal tumours and those with nonlaryngeal tumours was tested with a $\chi^{2}$ test.

Univariate analysis of the patients' survival was carried out using the Kaplan - Meier product-limit method (Kaplan and Meier, 1958 ) and log-rank comparison to evaluate the difference between the survival curves (Peto et al, 1977). The primary end points of survival analysis were disease-free survival (DFS) and diseasespecific survival (DSS). In the former case, the local and/or regional recurrence and/or systemic dissemination was considered as an event, whereas the latter was calculated by censoring deaths from disease-unrelated causes. The survival times were calculated from the date of surgery. Cystatin C concentrations were dichotomised into low and high groups after optimisation of the cutoff level, using the Critlevel method as described by Abel et al (1984). Multivariate analysis was performed according to Cox's proportional hazard model (Cox, 1972). All of the tests were twosided and the results were considered significant at a probability level below $5 \%$.
The study protocol was approved by the Medical Ethics Committee at the Ministry of Health of the Republic of Slovenia. All of the included patients gave their informed consent to voluntary participation in the study.

\section{RESULTS}

\section{Distribution of cystatin $\mathrm{C}$ concentrations and relation to clinical and histopathological parameters}

The concentrations of cystatin $\mathrm{C}$ in 82 tissue homogenates of tumour and corresponding nontumorous mucosa are summarised in Table 2. The cystatin $\mathrm{C}$ concentration was significantly $(\mathrm{P}<0.0001)$ decreased by a factor of 2.44 in $37(45 \%)$ tumours and was elevated 2.04 -fold in 45 cases (55\%), still resulting in a 1.18 -fold significant $(P=0.041)$ decrease in inhibitor concentration in the total population of tumour samples compared to their control counterparts. Furthermore, the cystatin C levels in control samples in the group where an increase was observed was significantly lower than in the control group with decreased inhibitor $(P<0.0001)$.

In normal mucosa samples, the cystatin $C$ level was influenced by the site of sampling, being lower in nonlaryngeal tissue samples (i.e., from the oral cavity, oropharynx or hypopharynx) than in the laryngeal ones (11.5 vs $\left.24.0 \mathrm{ng} \mathrm{mgp}^{-1} P=0.004\right)$. With regard to the cystatin $\mathrm{C}$ levels in tumour tissue or the distribution of downregulated and upregulated cases, no difference was found between these two major groups of tumours.

The data were further analysed with respect to the established clinical and histopathological parameters. No correlation was found between tumour cystatin C level on the one hand and, on the other hand, patients' age and sex, histopathological tumour grade, pT-stage and the overall UICC pTNM-stage of the disease, and the presence of tumour emboli in the lymphatic vessels as determined in a histological examination of a resected tissue specimen from the neck. The tumour cystatin $\mathrm{C}$ level correlated inversely with $\mathrm{pN}$ stage $\left(\mathrm{pN}_{0} v s \mathrm{pN}_{+}: 18.4\right.$ vs $\left.14.2 \mathrm{ng} \mathrm{mgp}^{-1}, P=0.047\right)$, whereas a trend of lower cystatin $C$ levels was observed in the group with extranodal tumour extention compared to that with no extranodal spread (14.0 vs $17.4 \mathrm{ng} \mathrm{mgp}^{-1}, P=0.069$ ).

The analysis was repeated separately on laryngeal and nonlaryngeal tissue samples. In matched pairs of normal mucosa and tumour tissue, statistically significant $(P=0.029)$ decrease in tumour cystatin $\mathrm{C}$ concentration was found in the group of laryngeal tumours: compared to the normal tissue counterparts,

Table 2 Concentrations of cystatin $C$ in tissue homogenates of tumours and adjacent normal mucosa

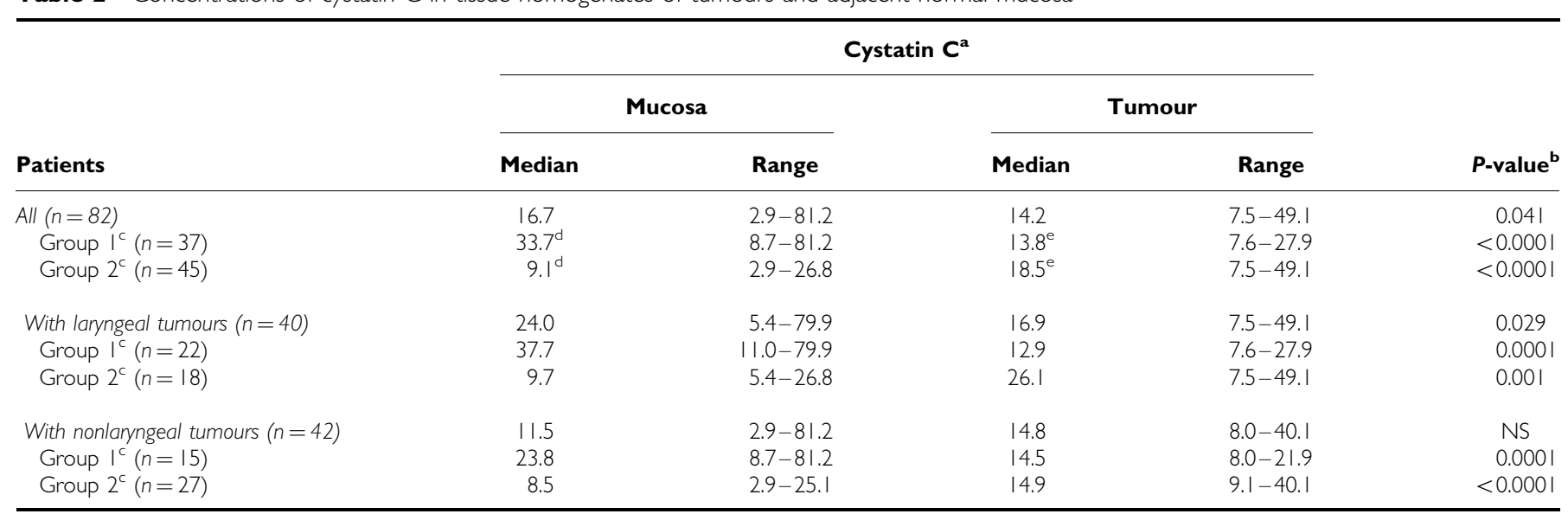

${ }^{a}$ Concentration, in $\mathrm{ng} \mathrm{mg}^{-1}$ total protein. ${ }^{\mathrm{b}}$ Mucosa vs tumour. ${ }^{\mathrm{C}}$ Patients with decreased (Group I) and increased (Group 2) concentration of cystatin $\mathrm{C}$ in tumour compared to mucosa. 'Mucosa: Group I vs Group 2, P<0.000I. ' Tumour: Group I vs Group 2, $P=0.009$. NS=not significant. 
the tumour cystatin $\mathrm{C}$ concentration decreased by a factor of 1.42 . The inhibitor decreased significantly $(P=0.0001), 2.92$-fold in $55 \%$ of tumours, and was elevated 2.69 -fold in $45 \%$ of cases (Table 2 ). No correlation with established clinical or histopathological prognostic factors was observed in this group of tumours. Among nonlaryngeal tumour samples, no difference was found in matched pairs of normal mucosa and its tumour counterparts, and marginally significant trend of higher cystatin $\mathrm{C}$ concentrations was observed in early disease compared to advanced tumours (UICC pTNM stages I-II vs III-IV: 18.1 vs $13.8 \mathrm{ng} \mathrm{mgp}^{-1}$, $P=0.052)$.

\section{Survival analysis}

As of 31 December 2002 (close-out date), disease relapsed in 22 patients and 50 patients died: 20 due to disease recurrence and/or dissemination and 30 due to causes other than the treated malignant disease. In total, 32 patients were alive with no signs of the disease. The median follow-up period of all eligible patients was 4.3 years (range: $0.1-10.0$ years), and was 6.5 years $(5.2-10.0$ years) for those alive at the last follow-up examination.

Actuarial DFS rates at 5 and 10 years were $70 \%$, and the DSS rates were $73 \%$. On univariate analysis, the patients with tumours involving neck nodes $\left(\mathrm{pN}_{+}\right)$and more advanced disease (overall UICC pTNM-stage), and those in whom extranodal tumour spread or tumour emboli were determined in the lymphatic vessels, exhibited a significantly higher risk of relapse or disease-specific death (Table 3 ). When using a median cystatin $\mathrm{C}$ concentration to classify tumours as cystatin C-low and cystatin C-high, no difference in survival was observed between the groups. However, after optimisation, the cystatin $C$ cutoff value was found to be the 68th percentile in the group and was identical for DFS and DSS, giving in both cases a $P$-value of 0.013 . As compared to the group with low tumour levels of cystatin $\mathrm{C}$, patients with higher tumour contents of the inhibitor experienced significantly longer survival (Table 3, Figure 1).

In multivariate analysis, the prognostic value of cystatin $\mathrm{C}$ was compared to the values of pN-stage, UICC pTNM-stage, extranodal tumour spread and the presence of tumour emboli in the lymphatic vessels. Variables were eliminated singly in a backward manner with exclusion if $P>0.050$. For DFS, pN-stage $(P=0.040$,
$\mathrm{HR}=2.78,95 \% \quad \mathrm{CI} \quad 1.25-6.38)$ and cystatin C $(P=0.043$, $\mathrm{HR}=0.22$, 95\% CI $0.08-0.66)$ were retained in the final model, and for DSS, pN-stage only $(P=0.011, \mathrm{HR}=4.36,95 \%$ CI $1.6-$ 9.55). In the latter case, cystatin $C$ turned out to be of marginal significance $(P=0.067, \mathrm{HR}=0.25,95 \%$ CI $0.07-0.90)$. As in the same cohort of patients stefin A has been identified previously as the most powerful prognosticator for both DFS and DSS, the standardised concentrations of the latter, calculated as described in our previous report, was also introduced in Cox model (Strojan et al, 2000). Using the Critlevel method, the concentrations of stefin A were dichotomised into low and high groups at cutoff level, which turned to be the 25th percentile in the group. Comparing both inhibitors, stefin A proved to be stronger and the only significant predictor for survival (DFS: $P=0.003, \mathrm{HR}=0.27$, $95 \%$ CI $0.11-0.63$; DSS: $P=0.004$, HR $=0.26,95 \%$ CI $0.11-0.65$ ).

In addition, to determine whether the combination of the two variables would increase the prognostic stratification of the patients, they were grouped as follows: high cystatin $\mathrm{C}$ and high stefin A - low-risk group (23 patients); high cystatin $C$ and low stefin $A$, or low cystatin $C$ and high stefin $A$ - medium-risk group (41 patients); and low cystatin $C$ and low stefin $A$ - high-risk group (18 patients). We found statistically highly significant difference between the three prognostic groups for both DFS and DSS $(P<0.0001$, Figure 2).

\section{DISCUSSION}

An alteration of the balance between cysteine cathepsins and their endogenous inhibitors has been demonstrated to correlate with neoplastic transformation, tumour invasion and metastasis (Sloane et al, 1994). The tissue and serum levels of these enzymes and inhibitors in a variety of human tumours have been shown to predict the disease-free and overall survival period, and may therefore serve as prognostic factors for cancer patients. However, the investigations mainly focused on cathepsins B and L, stefins, and the most frequent cancer types, that is, carcinoma of the breast, lung and colorectum (Kos and Lah, 1998). Much less is known about cystatin $C$, even though it has been used in clinical research studies for more than 20 years, preferentially as a candidate marker for detection of impaired glomerular filtration

Table 3 Univariate analysis of survival

\begin{tabular}{|c|c|c|c|c|c|c|c|}
\hline \multirow[b]{2}{*}{ Variable } & \multirow[b]{2}{*}{ No. of patients } & \multicolumn{3}{|c|}{ Disease-free survival } & \multicolumn{3}{|c|}{ Disease-specific survival } \\
\hline & & $\%$ at 5 years & $95 \% \mathrm{Cl}$ & $P$-value & $\%$ at 5 years & $95 \% \mathrm{Cl}$ & P-value \\
\hline \multicolumn{8}{|l|}{ pN-stage } \\
\hline $\mathrm{pN}_{0}^{\circ}$ & 37 & 89 & $76-100$ & 0.009 & 90 & $78-100$ & 0.008 \\
\hline $\mathrm{pN}_{+}$ & 45 & 61 & $43-79$ & & 59 & $40-78$ & \\
\hline \multicolumn{8}{|c|}{ UICC pTNM-stage } \\
\hline Stage $_{\text {-III }}$ & 34 & 87 & $73-100$ & 0.015 & 93 & $82-100$ & 0.001 \\
\hline Stage ${ }_{I V}$ & 48 & 57 & $40-74$ & & 58 & $4 I-75$ & \\
\hline \multicolumn{8}{|c|}{ Extranodal spread } \\
\hline Negative $^{a}$ & 52 & 82 & $69-95$ & 0.001 & 89 & $78-100$ & $<0.000 \mid$ \\
\hline Positive & 30 & 48 & $28-68$ & & 45 & $24-66$ & \\
\hline \multicolumn{8}{|c|}{ Tumour emboli } \\
\hline Negative $^{a}$ & 74 & 7I & $59-83$ & 0.027 & 75 & $63-87$ & 0.021 \\
\hline Positive & 8 & 27 & $5-49$ & & 25 & $2-48$ & \\
\hline \multicolumn{8}{|l|}{ Cystatin C } \\
\hline Low & 56 & 61 & $45-77$ & 0.013 & 64 & $48-80$ & 0.013 \\
\hline High & 26 & 90 & $76-100$ & & 91 & $78-100$ & \\
\hline
\end{tabular}

a Patients with no evidence of regional metastases (i.e. $\mathrm{pN}$ ) are also included. $\mathrm{Cl}=$ confidence interval. 


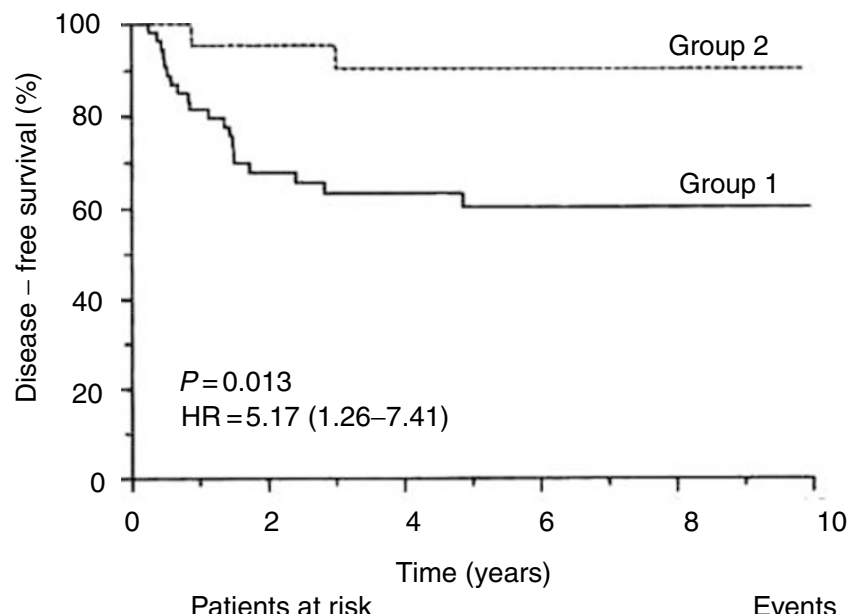

$\begin{array}{llllllll}\text { Group 1 } & 56 & 33 & 26 & 14 & 7 & 1 & 20 \\ \text { Group 2 } & 26 & 22 & 17 & 9 & 8 & 1 & 2\end{array}$

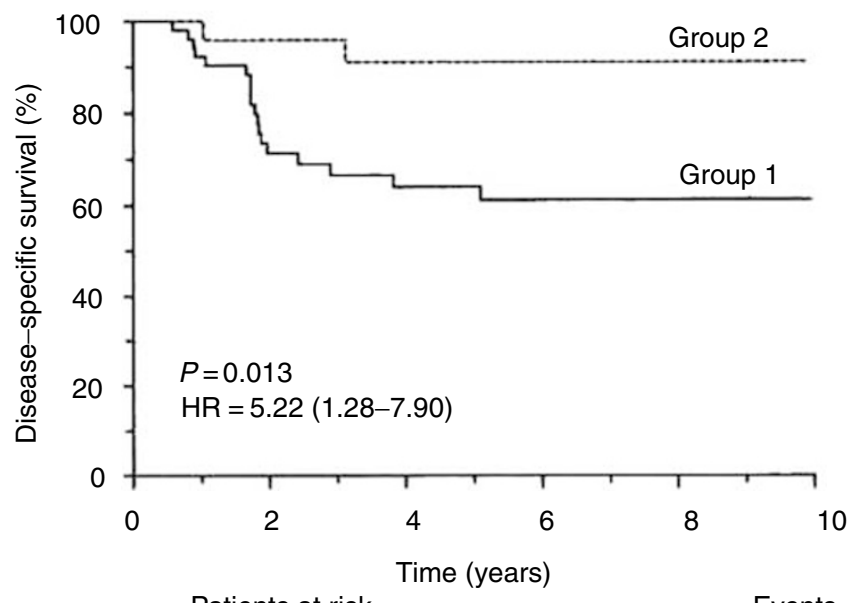

Patients at risk

Events

$\begin{array}{llllllll}\text { Group 1 } & 56 & 34 & 25 & 14 & 7 & 1 & 18 \\ \text { Group 2 } & 26 & 24 & 18 & 9 & 8 & 1 & 2\end{array}$

Figure I Actuarial DFS and DSS as a function of cystatin C concentration. The cutoff value was determined as described in the text. Numbers in parentheses indicate number of recurrences (or deaths)/total in each group.

rate (Newman, 2002). Based on high extracellular concentrations and inhibitory kinetics of cystatin $C$, it has also been shown as the most powerful extracellular inhibitor for several cysteine proteinases. Therefore, the majority of clinical work has been related to cystatin $\mathrm{C}$ activity and protein level determination in fluids surrounding tumours, mainly in the blood and urine (Kos et al, 2000b).

In the present study, a significantly lower concentration of cystatin $\mathrm{C}$ was found in the total population of tumour homogenates compared to normal mucosa, although two groups of patients with downregulated and upregulated cystatin $\mathrm{C}$ concentration were distinguished. At this point, the crucial question is whether the observed relations in cystatin $\mathrm{C}$ levels influenced the total intracellular proteolytic potential in the two groups. It has been shown that alterations in total inhibitory activity of cysteine proteinase inhibitors or in protein level in case

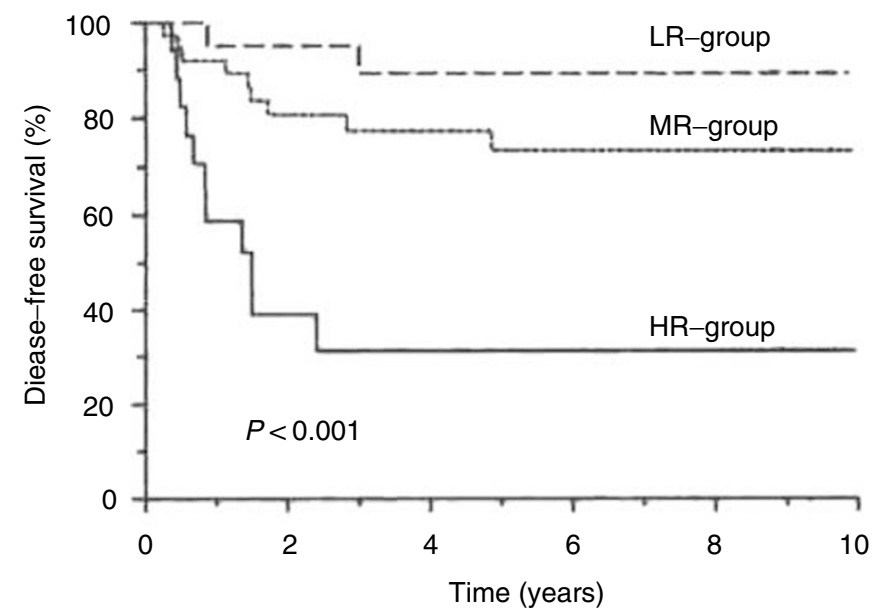

Patients risk

Events

$\begin{array}{lrrrrrrr}\text { HR-group } & 18 & 6 & 5 & 4 & 3 & 1 & 11 \\ \text { MR-group } & 41 & 28 & 23 & 12 & 5 & 1 & 9 \\ \text { LR-group } & 23 & 21 & 15 & 7 & 7 & 0 & 2\end{array}$

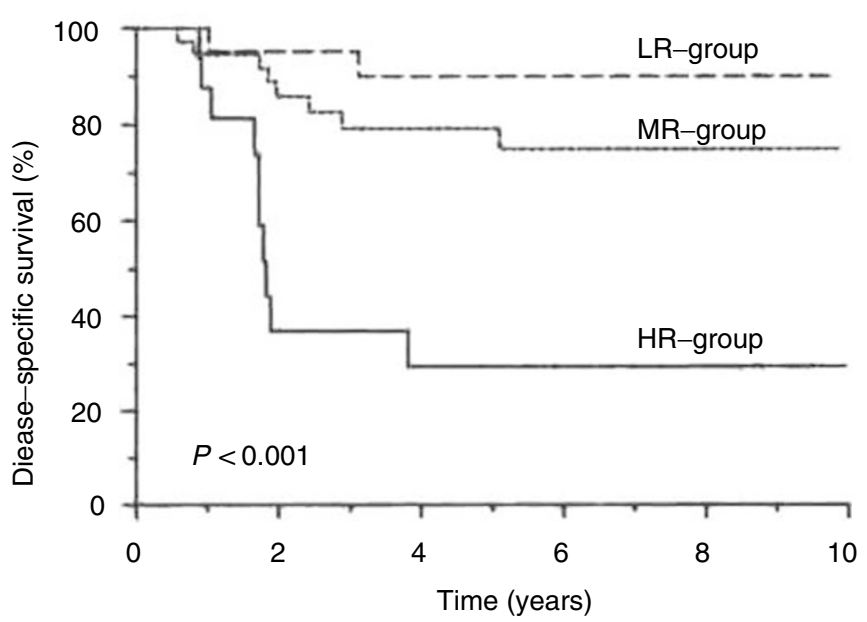

Patients risk

Events

$\begin{array}{lrrrrrrr}\text { HR-group } & 18 & 6 & 5 & 4 & 3 & 1 & 10 \\ \text { MR-group } & 41 & 31 & 23 & 12 & 5 & 1 & 8 \\ \text { LR-group } & 23 & 21 & 15 & 7 & 7 & 0 & 2\end{array}$

Figure 2 Prognostic significance of the combination of cystatin $C$ and stefin A concentrations: DFS and DSS. The cutoff value was determined as described in the text. Numbers in parentheses indicate number of recurrences (or deaths)/total in each group ( $L R=$ low-risk group; $\mathrm{MD}=$ medium-risk group; $\mathrm{HR}=$ high-risk group).

of stefin A were present in malignant tissue and normal parenchyma of the breast (Lah et al, 1992, 1997) and lung (Knoch et al, 1994). In the study by Lah et al (1992), lowered cysteine proteinase inhibitor activity in breast carcinoma tissue (i.e., in the low-activity group) was associated with significantly higher increases of cathepsin B and cathepsin L activities than those measured in the high-activity group, indicating higher proteolytic potential in the former group. In the low-activity group, more patients developed poorly differentiated and hormone receptornegative tumours. After a 2-year follow-up, however, recurrences were reported in the same percentage in both groups of patients. Neither in lung cancer (Knoch et al, 1994) nor in the present study (data not shown) was a significant difference between the two 
groups with respect to survival probability observed. In our study it is noteworthy that cystatin $\mathrm{C}$ level in control samples of the group of cystatin $\mathrm{C}$ positive tumours was significantly lower than in the control group with decreased inhibitor. Lah et al (1997), who reported on similar change for the inhibitory activity of cystatins and stefin A protein level in normal breast tissue, hypothesised that the relative increase in cystatin activity/levels was due to both an increase of cystatins in tumours and their decrease in control tissues. The latter suggested a downregulation of cystatin $C$ in stromal tissue adjacent to the tumour, possibly induced by tumour cells.

Specifically for cystatin C, alterations were described at various levels of protein synthesis. Yano et al (2001) reported on the tendency of lower cystatin C mRNA expression in breast cancer tissue than in noncancerous tissue, and significantly lower expression of cystatin $\mathrm{C}$ relative to cathepsin $\mathrm{B}$ in cancerous tissue. Downregulation of cystatin $\mathrm{C}$ gene was found in large granular lymphocyte leukaemia (Kothapalli et al, 2003). On the contrary, in squamous-cell lung cancer, no alteration in cystatin C protein level was described in matched pairs of normal and tumour tissue homogenates (Ebert et al, 1997; Køepela et al, 1998) and, in colorectal cancer, a similar cystatin C mRNA level was found in cancerous and noncancerous tissue, which tended to show an inverse correlation with the cathepsin B levels (Hirai et al, 1999). The possibility of a similar number of pairs with equally increased and decreased cystatin C mRNA or protein level in these studies, resulting in the same average, could not be excluded.

The correlation between cysteine proteinases, their inhibitors and tumour malignancy is likely to be a qualitative rather than a quantitative one. Thus, the proteolytic activity in tumours might be affected not only by the alterations in synthesis but also in processing, subcellular localisation and secretion of the enzymes and their inhibitors. As a result, in breast cancer, the cathepsin B and $\mathrm{L}$ activities were found to be much more increased than the respective protein levels, suggesting that the increase in activity was not entirely due to the induction of the respective proteins (Lah et al, 1997). The changes in molecular structure of inhibitors may decrease the binding affinity for the target enzymes, as described by Lah et al (1989) for stefin A in human sarcoma. In lung tumour tissue, cathepsin B was found to be more resistant to inactivation by E-64 than cathepsin B from control lung tissue (Křepela et al, 1995). Furthermore, it has been shown that the serum level of cathepsin $\mathrm{B} /$ cystatin $\mathrm{C}$ complexes was significantly decreased in patients with malignant lung tumours than in healthy controls (Zore et al, 2001). Additionally, higher total concentrations of cystatin $\mathrm{C}$ found in sera of patients with lung, colorectal and melanoma cancer (Kos and Lah, 1998) suggested enhanced secretion of cystatin $C$ from tumour cells, increasing at the same time the intracellular proteolytic potential of cysteine proteases. Association of enhanced secretion of cystatin C with invasive potential has been found in various cell lines (Kos et al, manuscript in preparation).

A large body of literature has been accumulated to suggest that cystatin C participated not only in the transformation of cells to a malignant state but also in tumour growth, invasion and metastasis. In cystatin C transfected B16 melanoma cells, the overexpression of inhibitor resulted in the inhibition of melanoma cell mobility and of the ability to penetrate artificial matrices by about 50\% (Sexton and Cox, 1997), as well as in the suppression of metastasis by at least 90\%, compared to controls (Cox et al, 1999). Similarly, the overproduction of active recombinant cystatin $\mathrm{C}$ resulted in a pronounced reduction in Matrigel invasion of murine squamous carcinoma cells (Coulibaly et al, 1999). In human glioblastoma cells, inverse correlation between cystatin $\mathrm{C}$ and tumour grade was observed (Konduri et al, 2002). The sencecystatin C transfected cells were also markedly less invasive than the control cells and, in nude mice, did not form tumours upon intracerebral injection. Furthermore, it was suggested that cystatin
$\mathrm{C}$ and cathepsin $\mathrm{B}$ interaction may participate in the modulation of the invasive phenotype of human colonic tumours (Corticchiato et al, 1992). In the mouse lymphosarcoma model, the cystatin C concentrations in the plasma and other tissues reliably reflected the changes in tumour volume following cytotoxic therapy (Poteryaeva et al, 2001). In our study, we observed inverse correlation between the tumour cystatin $\mathrm{C}$ level and more aggressive forms of the disease (i.e., involved neck nodes, extranodal tumour spread), which also links the alterations in cystatin C expression with the invasive behavior of SCCHN. The fact that the intracellular inhibitors of cysteine proteases regulate the degradation of extracellular matrix, a crucial step in invasion process, is apparently contradictive. However, it has been shown that the extracellular matrix can be internalised and partially degraded in the tumour cells (Szpaderska and Frankfater, 2001). The role of intracellular fraction of cystatin $C$ in regulating this process has to be distinct from those of stefins $\mathrm{A}$ and $\mathrm{B}$ due to different subcellular localisation and inhibitory profile against cysteine proteases.

There is good evidence that all nucleated cells constitutively express cystatin C. However, variability in the degree of cystatin C gene expression in different tissues, which could be further influenced by several factors, provides evidence for the differential regulation of cystatin $\mathrm{C}$ expression in different tissues (Newman, 2002). In the present study, the results of cystatin $C$ measurements in normal mucosa were influenced by the site of sampling. Cystatin $\mathrm{C}$ levels were significantly lower in the homogenates prepared from nonlaryngeal tissue samples than in the homogenates from the laryngeal tissue. Thus, considering the inherent variations in the regulation of proteolytic pathways between individual subsites inside the upper aerodigestive tract, at least two groups of tissues should be distinguished in further studies.

Concerning the results on survival in our study, two points should be stressed. To our knowledge, this is the only study evaluating the prognostic significance of cystatin C in SCCHN and no data are available at the moment for comparison. Second, the study population was quite homogenous in respect to the selection of the patients (all had operable tumours) and therapy. In multivariate analysis, only the prognostic power of the pN-stage of disease outweighs that of cystatin C. However, when comparing the prognostic strength of cystatin $\mathrm{C}$ with that of stefin $\mathrm{A}$, which emerged as the most significant prognostic factor in our previous study analysing the same population of patient, cystatin C lost its significant prognostic power for both DFS and DSS. In addition, the combination of the two inhibitors, cystatin C and stefin A, could further stratify the risk of adverse event as was the case with stefin B and cathepsin B in colorectal cancer (Kos et al, 2000a).

The correlation between high levels of tumour cystatin $\mathrm{C}$ and the longer survival of our patients concurs with the concept of protective role of high levels of cysteine proteinase inhibitors in tissue homogenates. This concept has been proposed following the survival results in the carcinoma of the breast (Lah et al, 1997), lung (Knoch et al, 1994; Ebert et al, 1997), and head and neck (Strojan et al, 2000). Two studies apparently contradict this assumption, specifically regarding cystatin C. In colorectal cancer (Kos et al, 2000a) and lung cancer (Kos et al, unpublished results), the patients with high serum levels of cystatin $C$ exhibited a significantly higher risk of death than those with lower levels of inhibitor, whereas a decreased metastatic spread was found in cystatin C deficient mice compared to wild-type mice (Huh et al, 1999). As mentioned above, alterations in secretion may result in higher extracellular and lower intracellular levels of cystatin $\mathrm{C}$ and, therefore, the reverse correlation of serum cystatin $\mathrm{C}$ with patients' survival is to be expected. On the other hand, one has to be aware that cysteine proteases and consequently their inhibitors are also involved in biological processes other than tissue remodelling during the progression of primary tumours, such as the regulation of inflammatory and immune responses (Chapman et al, 1997) or 
apoptosis (Jaattela, 1999), so that the lack of cystatin C at the systemic level may lead to a lower metastatic spread compared to wild-type animals.

In conclusion, our data indicate that cystatin $\mathrm{C}$ is implicated in the invasive behavior of SCCHN. The variations in regulation of proteolytic pathways seem to be the inherent characteristic of individual subsites inside the upper aerodigestive tract, which should be considered in further studies. Moreover, the protective role of high levels of cystatin $\mathrm{C}$ in tissue homogenates was suggested, as it had been proposed for some other cysteine proteinase inhibitors by the survival results in breast and lung cancer as well as in SCCHN. When comparing the prognostic strength of cystatin $\mathrm{C}$ to that of stefin $\mathrm{A}$, the latter emerged as significantly more reliable predictor for survival.

\section{REFERENCES}

Abel U, Berger J, Wiebelt H (1984) Critlevel: an exploratory procedure for the evaluation of quantitative prognostic factors. Methods Inform Med 23: $154-156$

Abrahamson M, Mason RW, Hansson H, Buttle DJ, Grubb A, Ohlsson K (1991) Human cystatin C: role of the N-terminal segment in the inhibition of human cysteine proteinases and in its inactivation by leucocyte elastase. Biochem J 273: 621-626

Azzopardi JG, Chepizk OF, Hartman WH (1981) International Histological Classification of Tumours No 2: Histological Typing of Breast Tumours. Geneva: World Health Organization

Bradford MM (1976) A rapid and sensitive method for the quantification of microgram quantities of protein utilizing the principle of protein-dye binding. Anal Biochem 72: 248-254

Chapman HA, Riese RJ, Shi GP (1997) Emerging roles for cysteine proteinases in human biology. Annu Rev Physiol 59: 63-88

Cimerman N, Trstenjak Prebanda M, Turk B, Popovič T, Dolenc I, Turk V (1999) Interaction of cystatin C variants with papain and human cathepsins B, H and L. J Enzyme Inhibition 14: 167-174

Corticchiato O, Cajot JF, Abrahamson M, Chan SJ, Keppler D (1992) Cystatin C and cathepsin B in human colon carcinoma: expression by cell lines and matrix degradation. Int $J$ Cancer 52: 645-652

Coulibaly S, Schwihla H, Abrahamson M, Albini A, Cerni C, Clark JL, Ng KM, Katunuma N, Schlappack O, Glössl J, Mach L (1999) Modulation of invasive properties of murine squamous carcinoma cells by heterologous expression of cathepsin B and cystatin C. Int J Cancer 83: $526-531$

Cox DR (1972) Regression models and life tables. J Roy Stat Soc 187: $187-220$

Cox JL, Sexton PS, Green TJ, Darmani NA (1999) Inhibition of B16 melanoma metastasis by overexpression of the cysteine proteinase inhibitor cystatin C. Melanoma Res 9: 369-374

Ebert E, Werle B, Jülke B, Kopitar-Jerala N, Kos J, Lah T, Abrahamson M, Spiess E, Ebert W (1997) Expression of cysteine proteinase inhibitors stefin A, stefin B, and cystatin C in human lung tumor tissue. Adv Exp Med Biol 421: 259-265

Ekiel I, Abrahamson M (1996) Folding-related dimerization of human cystatin C. J Biol Chem 271: 1314-1321

Foekens JA, Kos J, Peters HA, Krašovec M, Look MP, Cimerman N, Meijervan Gelder ME, Henzen-Logmans SC, van Putten WLJ, Klijn JGM (1998) Prognostic significance of cathepsins $\mathrm{B}$ and $\mathrm{L}$ in primary human breast cancer. J Clin Oncol 16: 1013-1021

Gaumann A, Hansen T, Köhler HH, Kommoss F, Mann W, Maurer J, Kirkpatrick CJ, Kriegsmann J (2001) The expression of cathepsins in osteoclast-like giant cells of an anaplastic thyroid carcinoma with tracheal perforation. Pathol Res Pract 197: 257-262

Hansen T, Petrow PK, Gaumann A, Keyszer GM, Otto M, Kirkpatrick CJ, Kriegsmann J (2001) Expression of cysteine proteinases cathepsins B and $\mathrm{K}$ and of cysteine proteinase inhibitor cystatin $\mathrm{C}$ in giant cell tumor of tendon sheath. Mod Pathol 14: 318-324

Hirai K, Yokoyama M, Asano G, Tanaka S (1999) Expression of cathepsin B and cystatin $\mathrm{C}$ in human colorectal cancer. Hum Pathol 30: 680-686

Huh CG, Håkansson K, Nathanson CM, Thorgeirsson UP, Jonsson N, Grubb A, Abrahamson M, Karlsson S (1999) Decreased metastatic spread in mice homozygous for a null allele of the cystatin $\mathrm{C}$ protease inhibitor gene. J Clin Pathol: Mol Pathol 52: 332-340

Jaattela M (1999) Escaping cell death: survival proteins in cancer. Exp Cell Res 248: $30-43$

Kaplan EL, Meier P (1958) Nonparametric estimation from incomplete observation. J Am Stat Assoc 53: 457-481

Knoch H, Werle B, Ebert W, Spiess E (1994) Imbalance between cathepsin B and cysteine proteinase inhibitors is of prognostic significance in human lung cancer. Int J Oncol 5: 77-85
Konduri SD, Yanamandra N, Siddique K, Joseph A, Dinh DH, Olivero WC, Gujrati M, Kouraklis G, Swaroop A, Kyritsis AP, Rao JS (2002) Modulation of cystatin $\mathrm{C}$ expression impairs the invasive and tumorigenic potential of human glioblastoma cells. Oncogene 21: $8705-8712$

Kos J, Krašovec M, Cimerman N, Nielsen HJ, Christensen IJ, Brünner N (2000a) Cysteine proteinase inhibitors stefin A, stefin B, and cystatin C in sera from patients with colorectal cancer: relation to prognosis. Clin Cancer Res 6: $505-511$

Kos J, Lah TT (1998) Cysteine proteinases and their endogenous inhibitors: target proteins for prognosis, diagnosis and therapy in cancer (review). Oncol Rep 5: 1349-1361

Kos J, Werle B, Lah T, Brunner N (2000b) Cysteine proteinases and their inhibitors in extracellular fluids: markers for diagnosis and prognosis in cancer. Int J Biol Markers 15: 84-89

Kothapalli R, Bailey RD, Kusmartseva I, Mane S, Epling-Burnette PK, Loughran TS (2003) Constitutive expression of cytotoxic proteases and down-regulation of protease inhibitors in LGL leukemia. Int J Oncol 22: $33-39$

Křepela E, Procházka J, Kárová B, Čermák J, Roubková H (1998) Cysteine proteases and cysteine protease inhibitors in non-small cell lung cancer. Neoplasma 45: 318-331

Křepela E, Procházka J, Mynař́íková $\mathrm{H}$, Kárová $\mathrm{B}$, Polák J, Čermák J, Roubková H (1995) Multiple forms of cathepsin B in human lung cancer. Int J Cancer 61: $44-53$

Lah TT, Clifford JL, Helmer KM, Day NA, Moin K, Honn KV, Crissman JD, Sloane BF (1989) Inhibitory properties of low molecular mass cysteine proteinase inhibitors from human sarcoma. Biochim Biophys Acta 993: $63-73$

Lah TT, Kokalj-Kunovar M, Štrukelj B, Pungerčar J, Barlič-Magajna D, Drobnič-Košorok M, Kastelic L, Babnik J, Golouh R, Turk V (1992) Stefins and lysosomal cathepsins B, L and D in human breast carcinoma. Int $J$ Cancer 50: $36-44$

Lah TT, Kos J, Blejec A, Frkovič-Georgio S, Golouh R, Vrhovec I, Turk V (1997) The expression of lysosomal proteinases and their inhibitors in breast cancer: possible relationship to prognosis of the disease. Pathol Oncol Res 3: 89-99

Lal H (1994) Biochemical studies in head and neck cancers. Clin Biochem 27: $235-295$

Lenarčič B, Krašovec M, Ritonja A, Olafsson I, Turk V (1991) Inactivation of human cystatin $\mathrm{C}$ and kininogen by human cathepsin D. FEBS Lett 280: $211-215$

Lignelid H, Collins VP, Jacobsson B (1997) Cystatin C and transthyretin expression in normal and neoplastic tissues of the human brain and pituitary. Acta Neuropathol 93: 494-500

Lignelid H, Jacobsson B (1992) Cystatin C in the human pancreas and gut: an immunohistochemical study of normal and neoplastic tissues. Wirchows Archiv Pathol Anat 421: 491-495

Look MP, van Putten WLJ, Duffy MJ, Harbeck N, Christensen IJ, Thomssen C, Kates R, Spyratos F, Fernö M, Eppenberger-Castori S, Sweep CGJF, Ulm K, Peyrat JP, Martin PM, Magdelenat H, Brünner N, Duggan C, Lisboa BW, Bendahl PO, Quillien V, Daver A, Ricolleau G, Meijer-van Gelder ME, Manders P, Fiets WE, Blankenstein MA, Broët P, Romain S, Daxenbichler G, Windbichler G, Cufer T, Borstnar S, Kueng W, Beex LVAM, Klijn JGM, O'Higgins N, Eppenberger U, Jänicke F, Schmitt M, Foekens JA (2002) Pooled analysis of prognostic impact of urokinasetype plasminogen activator and its inhibitor PAI-1 in 8377 breast cancer patients. J Natl Cancer Inst 94: 116-128

Merz GS, Benedikz E, Schwenk V, Johansen TE, Vogel LK, Rushbrook JI, Wisniewski HM (1997) Human cystatin C forms an inactive dimer during intracellular trafficking in transfected $\mathrm{CHO}$ cells. J Cell Physiol 173: $423-432$ 
Newman DJ (2002) Cystatin C. Ann Clin Biochem 39: 89-104

Peto R, Pike MC, Armitage P, Breslow NE, Cox DR, Howard SV, Mantel N, McPherson K, Peto J, Smith PG (1977) Design and analysis of randomized clinical trials requiring prolonged observation of each patients. II. Analysis and examples. Br J Cancer 35: 1-39

Poteryaeva ON, Falameeva OV, Zhanaeva SY, Svechnikova IG, Korolenko TA, Kaledin VI (2001) Role of cystatin C and cysteine proteinases in the development of mouse LS-lymphosarcoma. Bull Exp Biol Med 1: 675-677

Quon H, Liu FF, Cummings BJ (2001) Potential molecular prognostic markers in head and neck squamous cell carcinoma. Head Neck 23: $147-159$

Sexton PS, Cox JL (1997) Inhibition of motility and invasion of B16 melanoma by the overexpression of cystatin C. Melanoma Res 7: $97-101$

Sloane BF, Moin K, Lah TT (1994) Regulation of lysosomal endopeptidases in malignant neoplasia. In Biochemical and Molecular Aspects of Selected Cancers, Pretlow TG, Pretlow TP (eds). pp 411 -472. NewYork: Academic Press
Sobin LH, Wittekind Ch (1997) TNM Classification of Malignant Tumours. International Union Against Cancer (UICC). New York: Wiley-Liss

Strojan P, Budihna M, Smid L, Svetec B, Vrhovec I, Kos J, Skrk J (2000) Prognostic significance of cysteine proteinases cathepsins $B$ and $L$ and their endogenous inhibitors stefins $A$ and $B$ in patients with squamous cell carcinoma of the head and neck. Clin Cancer Res 6: 1052-1062

Strojnik T, Židanik B, Kos J, Lah TT (2001) Cathepsins B and L are markers in clinically invasive types of meningiomas. Neurosurgery 48: 598-605

Szpaderska AM, Frankfater A (2001) An intracellular form of cathepsin B contributes to invasiveness in cancer. Cancer Res 61: 3493-3500

Yano M, Hirai K, Naito Z, Yokoyama M, Ishiwata T, Shiraki Y, Inokuchi M, Asano G (2001) Expression of cathepsin B and cystatin C in human breast cancer. Surg Today 31: 385-389

Yoshimura K, Tsuchida T, Kawamoto K (2000) Expression of cathepsin B and cystatin $\mathrm{C}$ in the human adenohypophysis and in pituitary adenomas. Oncol Rep 7: 27-31

Zore I, Krašovec M, Cimerman N, Kuhelj R, Werle B, Nielsen HJ, Brünner N, Kos J (2001) Cathepsin B/cystatin C complex levels in sera from patients with lung and colorectal cancer. Biol Chem 382: 805-810 